\title{
El romanticismo de José Eustasio Rivera
}

\author{
I. EL ROMANTICISMO DE TIERRA DE PROMISION
}

Dara el estudio del romanticismo en José Eustasio Rivera no es posible prescindir de su obra poética, porque a través de los sonetos de Tierra de promisión se observa una tendencia romántica en progreso que es la que estalla en las páginas de La vorágine.

Para nosotros, del sentimentalismo melancólico y suave del poeta a la exaltación desesperada del protagonista de la novela no existe más que una diferencia cuantitativa, la que va de la llanura a la selva. Porque así como en Don Quijote hay mucho de Cervantes, en Arturo Cova parece haber no poco de Rivera.

La realidad es que Tierra de promisión se nos presenta como un sonetario parnasiano en marcha hacia ese subjetivismo que, sin dejar por ello el juego de color y de luz, lleva al poeta a identificar la vida del paisaje circundante con su propia sentimentalismo melancólico y vago. Esto es lo que advertimos ya, en el soneto prólogo, que surge como una síntesis de toda la obra:

Soy un grávido río, y a la luz meridiana ruedo bajo los ámbitos reflejando el paisaje; $y$ en el hondo murmullo de mi audaz oleaje se oye la voz solemne de la selva lejana. Flota el sol entre el nimbo de mi espuma liviana; y peinando en los vientos el sonoro plumaje, en las tardes un águila triunfadora y salvaje vuela sobre mis tumbos encendidos en grana. Turbio de pesadumbre y anchuroso y profundo, al pasar ante el monte que en las nubes descuella con mi trueno espumante sus contornos inuindo, 
y después, remansando bajo plácidas frondas, purifico mis aguas esperando una estrella que vendrá de los cielos a bogar en mis ondas. ${ }^{1}$

Pero lo peculiar es que además de esa esencia íntima del sentimentalismo del autor que en algunos de los versos anteriores advertimos, creemos ver también - quisiera o no decirlo Rivera- la clave fundamental de los elementos románticos empleados en el sonetario, es decir, la profunda e indefinible melancolía del poeta, como el río:

turbio de pesadumbre y anchuroso y profundo;

la vaga expectación de algo que ha de llegar, que se presiente, $y$ que al fin queda como velado en una sombra de ensueño:

purifico mis aguas esperando una estrella

que vendrá de los cielos a bogar en mis ondas;

$y$, por último, la estrecha relación recíproca entre paisaje y poeta, en la que bien aquél se refleja en éste:

vuelo bajo los ámbitos reflejando el paisaje,

o éste se vuelca sobre aquél:

al pasar ante el monte que en las nubes descuella

con mi trueno espumante sus contornos inundo.

De los tres elementos, los dos primeros son, sin embargo, de tal impreciso lirismo, que escapan acaso a la posibilidad de una interpretación profunda, debido a la brevedad natural de las composiciones; pero en nuestra opinión muestran claramente, en su misma melancolía e imprecisión, el sello indiscutible del romanticismo, to que al final de la obra parece el propio Rivera confesar cuando dice:

Sintiendo que en mi espíritu doliente

la ternura romántica germina, voy a besar la estrella vespertina sobre el agua ilusoria de la fuente. 
De modo que, en términos generales, el impreciso subjetivismo del poeta es lo predominante, en un como rebose emocional que no hallara cauce.

Véase ahora un ejemplo palpable de lo que decimos en el terceto que dice:

Inspirado en un sueño de ternuras lejanas acaricio las flores, me corono de lianas, y los troncos abrazo con profunda emoción...

que también Chateaubriand - a quien Rivera, en prosa y verso, nos recuerda a veces- tiene en forma muy semejante, aunque más diáfana, cuando hace decir a René:

Faltábame un ser que llenase el abismo de mi existencia: bajaba a los valles, subía a las montañas, y llamando con toda la fuerza de mis deseos al objeto ideal de un amor futuro, lo abrazaba en los vientos, creía escucharlo en el murmullo de las aguas; todo era para mí ese imaginario fantasma: los astros en los cielos, y el principio mismo en el universo. 2

¿Hay, pues, en el colombiano, la ausencia de ese ser que ha de llenar los abismos del alma, la búsqueda de ese romántico objeto ideal siempre en fuga de sus brazos? Creemos que sí, porque tal es la impresión que casi invariablemente nos produce el poeta al aparecer en sus versos; y porque a través de las páginas del novelista lo veremos también en la angustia de Arturo Cova.

Pletórico, pues, de tal íntima riqueza emotiva no podemos esperar en el autor de Tierra de promisión, sino una subsiguiente reacción sentimental ante las variaciones del paisaje -acaso el más poderoso factor romántico en la colección de sonetos-, de acuerdo siempre, indiscutiblemente, con el propio clima espiritual del poeta; reacción en la que el crepúsculo, con todo su místico ambiente de luces y de sombras, caro a la ensoñación y al libre vuelo emocional, habrá de ejercer una especial atracción propicia al rebose lírico.

Embozado en la sombra se destaca el farallón; y la espesura inmensa, al borrarse el crepúsculo condensa un rumor perfumado de albahaca.

Algo se muere entre la fronda opaca; 


\begin{abstract}
gime el apuhil, la guacamaya piensa;
lloran lánguidas voces y en la densa quietud, boga un lucero en la resaca.

Rendido ante el dolor de la penumbra, mi ser que es una luz se apesadumbra; después con los murientes horizontes me voy desvaneciendo, me evaporo... y mi espíritu vaga por los montes como una gran luciérnaga de oro.
\end{abstract}

Es que el poeta, en tal forma hermanado con la naturaleza, no hace sino desplazar hacia ella todo el caudal de sus sentimientos, que convierte así en visión externa de su emoción interna.

De las relaciones de índole psicológica que existen entre el objeto y el sujeto de la intuición estética -dice García Prada-, quizás la más notable es la que los estetas alemanes llaman "de einfuehlung", que es común al arte y a la vida... En su apariencia el "einfuehlung" es un proceso psicológico que se caracteriza por la tendencia natural y universal del hombre a objetivar inconscientemente la emoción o impresión que una cosa externa ocasiona en su psiquis. Es un proyectar en el telón de lo externo, lo que no es sino meramente interno, subjetivo, psíquico $\ldots{ }^{3}$

$\mathrm{Y}$ es allí donde va a residir el origen de la naturaleza amiga de que habla el romántico, el origen de la ensoñación - reverie-, y el efecto del paisaje en Rivera.

Ya dijo en alguna parte Antonio Gómez Restrepo, que el espíritu nacional de su país poseía, sobre un fondo romántico, aficiones clásicas. En Rivera observamos algo semejante, porque si bien en gran parte de sus composiciones es parnasiano, objetivo, sin sentimiento alguno - si se prefiere-, cuando su personalidad entra al verso, y es también en no poca medida, su temperamento de íntima tonalidad elegíaca, hasta entonces reprimido, se vierte sobre la naturaleza que canta, tiñéndola toda con los suaves efluvios de su alma triste.

Ahora bien, el poeta clásico pođrá mostrar a ratos una tendencia hacia el sentimiento romántico del paisaje, aunque no sea lo característico de su escuela; pero nunca con la intensidad y la frecuencia de nuestro autor. 
Si tratáramos de generalizar podríamos decir que, ante la naturaleza, el clásico tiene sólo el objetivismo de la enumeración; mientras el romántico posee siempre el subjetivismo de la reacción. Ya ejemplificó José Enrique Rodó esa diferencia fundamental, en su paralelo entre un poeta de corte clásico, Andrés Bello, y otro de inspiración romántica, José María Heredia. ${ }^{4}$

Rivera no sólo insiste en esa característica ya mencionada de reacción sentimental al estímulo externo, sino que, ampliando la perspectiva elegíaca romántica en los estados emocionales que a la naturaleza en sí atribuye, va a prestar a la composición una mayor intensidad subjetiva que parece adelantarnos la técnica de $L a$ vorágine, en lo que respecta a la visión desorbitada de la selva.

Véase, por ejemplo, en el siguiente soneto, la presencia de ambas modalidades:

Cuando apagan los cielos su arrebol de verano desfallece $\mathrm{mi}$ alma con la luz vespertina; y al mugir de los toros en la loma vecina me contagia sus viejas pesadumbres el llano. Entre azules luciérnagas fosforece el pantano; a mi diestra mi sombra vacilante camina, y ante el santo lucero de la tarde se inclina una palma, en la ceja del poniente lejano. Ya se quejan las ranas ... el paisaje se esfuma, $y$ en mi ser y en los campos va cayendo la bruma; sobre el cerro columbro de una hoguera el fanal, $\mathrm{y}$ al sentir que algo inmenso y angustioso me llena, lanzo un grito! ... Y entonces, compartiendo mi pena, se remonta una garza del borroso juncal.

Adviértase cómo Rivera intensifica gradualmente su reacción sentimental al estímulo del paisaje:

desfallece mi alma con la luz vespetrina... me contagia sus viejas pesadumbres el llano...

y en mi ser y en los campos va cayendo la bruma...

hasta que estallando la fuerte carga emocional del poeta y al sentir que algo inmenso y angustioso me llena lanzo un grito... 
se establece como una especie de círculo subjetivo por el que el medio exterior reacciona a su vez ante el hombre:

$\mathrm{Y}$ entonces, compartiendo mi pena, se remonta una garza del borroso juncal.

Es así como se nos presenta con claridad meridiana todo el recorrido de una corriente simpática establecida entre el poeta y el paisaje. El procedimiento no es usual, por supuesto, ya que el poeta por regla general prescinde de mostrarnos su itinerario sentimental; pero, en nuestra opinión, of rece magistralmente el porqué de la vida emocional advertida, como en un ser humano, en la naturaleza de Tierra de promisión.

Esto nos muestra que Rivera no sólo se identifica con las variaciones de la naturaleza sino que la anima prestándole reacciones emotivas, como las que ejemplifican en el soneto anterior "las viejas pesadumbres del llano", o aquella garza que remonta el vuelo "compartiendo mi pena". $\mathrm{Y}$ todo, porque lo que el poeta en realidad hace - he aqui un aspecto típico del romanticismo- es captar la propia tonalidad triste y amarga de su alma.

El soneto que vamos ahora a reproducir, donde el poeta ni siquiera aparece, aunque lo sabemos allí, absorto ante el paisaje e identificándolo con su propia alma, es una muestra característica de lo que decimos:

\footnotetext{
Hay un agua salobre y solitaria, que al volcarse la rica cornucopia de la noche lunar apenas copia borrones de celeste luminaria. Soñando en una fuente tributaria, huérfana de caricias, soliloquia; y alza débil rumor, con esa propia humildad que enaltece a la plegaria. Entonces, bajo el oro del ocaso, alguna vaca de solemne paso atraviesa el yerbal de la comarca, y, adormeciendo la pupila oscura, besa, con melancólica ternura, la inconsolable linfa de la charca.
} 
He aquí, pues, la forma en que Rivera subjetiviza esa naturaleza que lo rodea, hasta el punto de atribuirle sentimientos y reacciones humanos. Para él, la charca y el cuadrúpedo se sublimizan, viven emocionalmente, y expresan, por consiguiente, en toda la avidez de ternuras de la una o en el dulce consuelo de la otra, esa existencia sentimental que en realidad no poseen.

De modo que el colombiano podrá ser, como en términos generales han expresado algunos críticos, un poeta descriptivo de índole parnasiana; pero es también un poeta en quien no falta esa peculiar melancolía íntima e indescriptible, esa profunda reacción sentimental ante el paisaje, tan características del movimiento literario a que nos referimos.

Por todo eso, el romanticismo de Tierra de promisión, diverso en realidad del observado en La vorágine, va a ser de un tono elegíaco, suave, crepuscular, indefinible.

\section{DE TIERRA DE PROMISION Y LA VORAGINE}

Al adentrarnos en las páginas de La vorágine, la propia forma de la obra parece mostrarnos ya su filiación romántica; porque, como ha dicho Juan Marinello, "el modo autobiográfico será siempre una irresistible invitación a lo confidencial." 5 Y en ello reside la predilección romántica por las memorias, por los diarios, como advertimos en Rousseau, Chateaubriand, Goethe, Jorge Isaacs y tantos otros.

Pero atu por sobre la mera forma autobiográfica, que siendo en La vorágine algo más que pura ficción literaria no es siempre por sí misma condición de romanticismo, la crítica ha advertido también - $y$ he aquí las semejanzas de autor y héroe- ese fuerte lirismo de Rivera, natural en un hombre que "trabaja bajo una inmensa pasión, posee una arrebatada fantasía, carece de humorismo y" cuya "visión de las cosas se agiganta como sus sentimientos."

Ante semejante paralelismo de Rivera y Cova, no es posible considerar al segundo como a un simple personaje exaltado y pasional, creado por la fantasía del novelista; tampoco es mera coincidencia la del héroe-poeta que, como el Werther de Goethe, narra un pasaje real de la vida del autor. Para nosotros Rivera era 
de una intima idiosincracia romántica que en la novela lo llevó a retratarse en gran medida en su protagonista, como se observará en la similaridad de la reacción sentimental ante el paisaje, y en el énfasis de los motivos crepusculares, llevados hasta el extremo de que Rivera parece repetirse en ocasiones.

Recuérdese, por ejemplo, del soneto IV, parte tercera, transcrito en páginas anteriores, los siguientes versos:
cuando apagan los cielos su arrebol de verano desfallece mi alma con la luz vespetrina; y al mugir de los toros en la loma vecina me contagia sus viejas pesadumbres el llano.
Ya se quejan las ranas... el paisaje se esfuma, y en mi ser y en los campos va cayendo la bruma.

o del número xvirI, parte primera, también transcrito:
Rendido ante el dolor de la penumbra, mi ser, que es una luz, se apesadumbra, después con los murientes horizontes me voy desvaneciendo, me evaporo... y mi espíritu vaga por los montes como una gran luciérnaga de oro.

y compárese lo anterior con el siguiente pasaje de La vorágine:

Mientras proseguíamos silenciosos principió a lamentarse la tierra, por el hundimiento del sol, cuya vislumbre palidecía sobre las playas. Los más ligeros ruidos repercutieron en mi ser, consustanciado a tal punto con el ambiente, que era mi propia alma la que gemía, y mi tristeza la que, a semejanza de un lente opaco, apenumbraba todas las cosas.

Sobre el panorama crepuscular fuese ampliando mi desconsuelo, como la noche, y lentamente una misma sombra borró los perfiles del bosque extático, la línea del ‘agua inmóvil, las siluetas de los remeros... ${ }^{7}$

Tanto en el poeta como en el protagonista de la novela vemos, pues, una similar identificación de hombre y paisaje, que es lo que hermana a autor y héroe en esa peculiar actitud del romanticismo, paralelismo que volvemos a hallar en el empleo de la palabra "romántico" como expresión de un estado emocional. 
En tal sentido dirá Rivera en Tierra de promisión:

Sintiendo que en mi espiritu doliente

la ternura romántica germina,...

y Arturo Cova, tras el episodio del garcero:

Aquella tarde rendí mi ánimo a la tristeza y una emoción romántica the sorprendió con vagas caricias: 8

Lo que nos muestra que el suave lirismo de ambos poetas, el de la vida real y el de la ficción, es esencialmente el mismo, alterado tan sólo en el segundo, por el maridaje de la pasión y de la selva, en una como desorbitación de aquel sentimiento elegíaco tan propio de Tierra de promisión, y no ausente de La vorágine ni siquiera en lo que respecta a la visión puramente subjetiva, y casi invariablemente melancólica, del paisaje.

Recordemos algunos ejemplos de Tierra de promisión:

templa el indio desnudo la vibrante correa y se quejan las brisas al pasar el flechazo...

y al momento una guadua, inclinándose en arco, afligida se queda santiguando las ondas.

Con pausados vaivenes refrescando el estío, la palmera engalana la silueta llanura; y en su lánguido ensueño, solitaria murmura ante el sol moribundo sus congojas al río. Encendida en el lampo que arrebola el vacío, presintiendo las sombras, desfallece en la altura, $y$ sus flecos suspiran un rumor de ternura cuando vienen las garzas por el cielo sombrio.

Utilicemos ahora, de La vorágine, otros dos ejemplos característicos :

Buscábamos el abrigo de los montes lontanos, y salimos a una llanada donde gemian las palmeras ... ${ }^{9}$

Sollozando en la oscuridad, pasaba una corriente desconocida. Era el Isana. 10

$Y$ terminemos estas citas con dos fragmentos en los que veremos una vez más otra de esas estrechas semejanzas entre el libro de versos y la novela. 
En el soneto número XXI, tercera parte, dice Rivera:

... oigo como una voz ultradivina

de alguieñ que me celara en el ambiente

y al pensar que tu espíritu me asiste,

torno los ojos a la pampa triste;

Nadie !... Sólo el crepúsculo de rosa.

Mas iay! que entre la tímida vislumbre, inclinada hacia mí con pesadumbre suspira una palmera temblorosa.

que en La vorágine corresponderá al siguiente pasaje:

La brisa del anochecer refrescaba el desierto, y de repente, en intervalos desiguales, llegó a mis oídos, algo como un lamento de mujer. Instintivamente pensé en Alicia, que acercándose me preguntaba:

- ¿Qué tienes? ¿Qué tienes?

Reunidos después, sentíamos la sollozante quejumbre, vueltos hacia el lado de donde venía, sin que acertáramos a descifrar el misterio: una palmera de macanilla, fina como un pincel, obedeciendo a la brisa, hacía llorar sus flecos en el crepúsculo. 11

En todo lo anterior vemos, por consiguiente, que bajo el temperamento apasionado del escritor colombiano se anidaba un suave sentimentalismo crepuscular - con metáfora y sin ella - característico del romanticismo de Tierra de promisión e innegable aun bajo la exaltación de Arturo Cova; aunque la nota fundamental de $L a$ vorágine va a estar realmente en el desplazamiento de esa suave melancolía romántica del sonetario hacia las tonalidades más avanzadas de un romanticismo centrado en la pasión desorbitada, en la fantasía sin frenos, en la búsqueda inevitable de lo que no se encuentra y, como síntesis, en esa exaltación del Yo de que no podía prescindir el personaje romántico.

\section{ARTURO COVA Y EL DESEQUILIBRIO PASTONAL ROMANTICO}

Desde las primeras líneas de La vorágine Arturo Cova se nos presenta ya en toda su íntegra personalidad, tanto en el fragmento de su carta, en el que "el destino implacable" tiene un papel tan fundamental, como en el propio comienzo de la obra: 
Antes que me hubiera apasionado por mujer alguna, jugué mi corazón al azar y me lo ganó la Violencia. Nada supe de los deliquios embriagadores, ni de la confidencia sentimental, ni de la zozobra de las miradas cobardes. Más que el enamorado, fuí siempre el dominador cuyos labios no conocieron la súplica. Con todo, ambicionaba el don divino del amor ideal, que me encendiera espiritualmente, para que mi alma destellara en mi cuerpo como la llama sobre el leño que la alimenta...

En vano mis brazos -tediosos de libertad- se tendieron ante muchas mujeres implorando para ellos una cadena. Nadie adivinaba mi ensueño. Seguía el silencio en mi corazón. ${ }^{12}$

Y más tarde, recordando sus palabras a Alicia:

¿Cómo podría desampararte? ¡Huyamos! Toma mi suerte, pero dame el amor. ${ }^{13}$

La carta y los párrafos transcritos de la introducción, no son otra cosa que un torrente de apasionado sentimentalismo romántico. El "destino implacable" del fragmento, el juego al azar de un corazón ganado por la violencia, el añorado don divino del amor ideal, la incomprensión ajena para los sueños del poeta, el "Toma mi suerte, pero dame el amor", no es sino romanticismo, y del desesperado que llevó al Werther de la ficción o al Larra de la realidad a dispararse un pistoletazo.

De modo que a través de toda la obra vamos a ver la misma actitud sentimental, donde la pasión y el desenfreno emocional, sin dominio alguno de la razón, arrastrarán al protagonista. Es que el romanticismo fué -y es- precisamente el desconcierto de la personalidad bajo el dominio de lo irracional, la exaltación de la sensibilidad y del instinto por sobre lo racional. ${ }^{14}$ En otras palabras, y como dice el propio Arturo Cova, marchar siempre, "contrariando la reflexión" aun a riesgo de ser llamado por todos "un desequilibrado tan impulsivo como teatral." Porque "evidentemente, ciertos actos, como que se anticipan a mis ideas: cuando el cerebro manda, ya mis nervios están en acción." 15

Ahora bien, como observa Irving Babbit, "the man who makes selfexpression and not selfcontrol his primary endeavor becomes subject to every influence", es decir, y cita a Byron, "the very slave of circumstance and impulse borne by every breath." 16 
Tal es la causa de la inestabilidad que advertimos en los caracteres románticos, y que pudiéramos ejemplificar en exceso.

Recordemos el Rousseau de Las confesiones:

... véase ahora otra de mis diferencias características. En los momentos en que más sujeto me tiene un hábito, la cosa más pequeña me distrae, me cambia, me domina, y por fin me apasiona; entonces todo queda olvidado; sólo pienso en el nuevo objeto que me preocupa. ${ }^{17}$

O el René de Chateaubriand:

Mi carácter era impetuoso y desigual. Alternativamente bullicioso y alegre, o taciturno y triste, ora reunia en mi derredor a mis jóvenes compañeros, ora los abandonaba súbitamente... ${ }^{18}$

$\mathrm{Y}$, por último, el Werther de Goethe:

¿No es posible que tú hayas visto nada de tan desigual, de tan inquieto, como este corazón; pero tengo yo necesidad de decírtelo a ti, amigo mío, que has sufrido tantas veces al verme pasar tan a menudo, de una negra preocupación a una loca extravagancia; de una dulce melancolía al furor de una pasión? 19

Todo esto es lo que vamos a encontrar en la odisea de Arturo Cova, y en sus propias palabras:

Frecuentemente las impresiones logran su máximum de potencia en mi excitabilidad, pero una impresión suele degenerar en la contraria a los pocos minutos de recibida. Así, con la música, recorro la gama del entusiasmo para descender luego a las más refinadas melancolías; de la cólera paso a la más transigente mansedumbre, de la prudencia, a los arrebatos de la insensatez. En el fondo de mi ánimo acontece lo que en las bahías: las mareas suben $y$ bajan con intermitencia. 20

Tal abandono a los caprichos de la sensibilidad, de la pasión, es, pues, lo que convierte al romántico -al romántico de vuelta ya de todos los caminos- en un ser desorbitado y hasta sin concepto alguno del límite que todo hombre normal advierte entre la bondad y la maldad, entre la justicia y la injusticia, entre la compasión y el sadismo.

Para ese romanticismo "esencial", no existe más que el Yo y su sensibilidad: sentir siempre, embriagarse de sensaciones y vivir, 
en la más completa desnudez de toda autocritica que ponga barreras a la pasión, la aventura que brinda un manjar no gustado jamás.

Al alcanzar este punto estamos ya a las puertas de una sensibilidad morbosa; en el momento de arrostrar no simplemente la exageración sino la enfermedad, ${ }^{21}$ de ahi el llamado satanismo romántico, a veces en sentido figurado y otras propio, de que no nos faltan ejemplos en La vorágine:

¿Por qué no ruge toda la selva y nos aplasta como a reptiles para castigar la explotación vil? :Aquí no siento tristeza, sino desesperación! i Quisiera librar la batalla de las especies, morir en los cataclismos, ver invertidas las fuerzas cósmicas! iSi Satán dirigiera esta rebelión...! 22

$Y$ en uno de esos momentos de embriaguez ante la sensación de lo horriblemente novedoso, exclama:

La visión frenética del naufragio me sacudió con una ráfaga. de belleza. El espectáculo fué magnífico. La muerte había escogido una forma nueva contra sus víctimas...

Mientras corríamos por el peñasco a tirar el cable de salvamento, en el ímpetu de una ayuda tardía, pensaba yo que cualquiera maniobra que acometiéramos aplebeyaría la imponente catástrofe; y, fijos los ojos en la escollera, sentía el dañino temor de que los náufragos sobreaguaran, hinchados, a mezclarse en la danza de los sombreros. 23

En situaciones como las que acabamos de ejemplificar es cuando arribamos a uno de los aspectos de esa fase avanzada y típica del romanticismo, en la que el hombre se entrega por completo al capricho de lo irracional, es decir, al más franco dominio de los instintos. Y siendo en esa completa libertad del instinto, de la pasión, donde residen para el romántico las más puras formas de la personalidad sin trabas ni adulteraciones exteriores, resultado de su peculiar exaltación de lo individual, hallaremos siempre en él una actitud favorable hacia todo lo que lleve el sello de la osadía, de la insurgencia, de lo diferenciador, aunque el héroe sea, como observa Irving Babbit, Caín o Satanás. ${ }^{24}$

Por ello, y aunque maldiciéndolos, no podrá Arturo Cova evitar su admiración por la sangrienta "epopeya de esos piratas" que con "un valor magnífico" 25 tiranizan la selva. 
Tal es, por consiguiente, el Arturo Cova impulsivo y desorbitado que, sentimental y variable, sin embargo, sabrá también llorar, como todo romántico, al levantar el velo del recuerdo; ante el nombre de la mujer que lo ha abandonado; al pensar, en fin, en todo lo que pudo haber sido y ya no será jamás.

\section{LA FANTASIA, EL IDEAL FEMENINO Y EL DESTINO ROMANTICOS}

De la propia anárquica libertad emocional y junto al desequilibrio pasional que ella produce, va a surgir también el vuelo irrefrenable de la fantasía romántica, que nos sitúa en una vida de encantadora placidez o se adelanta generalmente a los hechos creando un magnífico mundo de ensueños acorde con los deseos de su creador.

Pero como sucede que el romanticismo se apoya precisamente en esa anárquica libertad emocional que hemos mencionado antes, es decir, en to irreflexivo, en la dependencia de circunstancias meramente exteriores que lo dominan en un momento determinado, la imaginación del romántico modela realmente a su arbitrio los acontecimientos futuros; mas esto es sólo hasta que un nuevo hecho, con tanta violencia como el anterior, hiere la conciencia del individuo.

En este sentido el representante típico, y probablemente sin paralelo en todo el movimiento, es Juan Jacobo Rousseau, cuyas Confesiones nos muestran innumerables pasajes de tal naturaleza en los que unas veces se ve a punto de arrostrar aventuras singulares, de hallar tesoros o de triunfar en la vida social; y otras, ya mariscal o músico eminente.

Tomemos como ejemplo característico de tal actitud el siguiente pasaje de su primer viaje a París:

Me hacían compañía mis gratas quimeras, y nunca las imaginó más bellas mi ardiente fantasía...

Esta vez eran marciales mis ideas. Tba a juntarme con un militar y a serlo yo también, pues se había tratado que yo entraría de cadete. Ya me veía vestido con el uniforme de oficial... Mi corazón se dilataba con ese noble pensamiento... Ofrecía algún obstáculo mi corta vista, pero no me apuraba por esto, y contaba suplir esta falta a fuerza de intrepidez y sangre fría. Había leído que el mariscal Schomberg era muy corto de vista ¿ por qué no había de poder serlo el mariscal Rousseau? 26 
Ahora bien, si con semejantes antecedentes volvemos los ojos a la novela de Rivera hallaremos también no pocas ocasiones en las que Arturo Cova se nos presenta como un caso típico de soñador romántico, a veces asombrosamente cercano al de Rousseau.

Hemos contado hasta cinco de estos pasajes que podemos considerar capitales, todos de considerable extensión y perfectamente representativos de lo que venimos diciendo, y por ellos advertimos la constante tendencia del protagonista hacia una ensoñación que anticipa el futuro con tal vigor de hecho consumado que maravilla.

Ya desde el comienzo de la obra, y donde ni siquiera puede hacerse la más mínima insinuación en lo que respecta a posibles efectos producidos por la selva, Cova se entusiasma con la perspectiva de un negocio ganadero, para ofrecernos uno de sus sueños característicos que vamos a reproducir pese a su extensión:

Cuando Alicia y don Rafael salieron al patio, abrió mi fantasía las alas:

Me ví de nuevo entre mis condiscípulos, contándoles mis aventuras de Casanares, exagerándoles mi repentina riqueza, viéndolos felicitarme, entre sorprendidos y envidiosos. Los invitaría a comer a mi casa, porque para entonces tendría una, propia... Con frecuencia Alicia nos dejaría solos, urgida por el llanto del pequeñuelo, llamado Rafael, en memoria de nuestro compañero de viaje. Mi familia, realizando un antiguo proyecto se radicaría en Bogotá; $y$ aunque la severidad de mis padres los indujera a rechazarme, les mandaría a la nodriza con el pequeño los días de fiesta. Al principio se negarían a recibirlo, mas luego mis hermanas, curiosas, alzándolo en los brazos, exclamarían: " $i$ Es el mismo retrato de Arturo!" Y ni mamá, bañada en llanto, lo mimaría gozosa, llamando a mi padre... mas el anciano, inexorable, se retiraría a sus aposentos, trémulo de emoción.

Poco a poco, mis buenos éxitos literarios irían conquistando el indulto. Según mi madre debía tenérseme lástima. Después de mi grado en la Facultad se olvidaría todo. 27

Si por la lectura del pasaje anterior se advierte esa indudable relación ya mencionada entre la fantasía del Rousseau de Las confesiones y la del héroe de Rivera, para quienes la sombra de Don Quijote no parece andar muy lejana, no sería difícil citar otros casos donde al simple y típico fantasear romántico se aunan la exaltación del Yo o la búsqueda obsesionante del ideal femenino, elementos también muy propios del movimiento. 
Sin embargo, la presencia de ambos caracteres no se reduce a esos momentos de incontrolable vuelo imaginativo; sino que se extiende por toda la novela con inconfundible frecuencia e intensidad.

Para el romanticismo hay quizás dos formas fundamentales de exaltación de la personalidad; el culto al héroe -endiosamiento del individuo, del Yo-; y la preferencia por lo diferenciador, que es con frecuencia una simple fase de lo anterior.

Cuando Cova comienza a modelar su plan para, valiéndose de un ardid, enviar uno de sus amigos al cónsul colombiano en Manaos, haciéndole saber la verdadera situación de sus compatriotas en los siringales, vamos a encontrar, junto al elemento imaginativo rousseauniano, una muestra de esa primera forma que llamamos del culto al héroe.

En este caso el adversario será el sanguinario prófugo de la justicia conocido por el sobrenombre de El Cayeno, y el poeta termina su meditación en la forma siguiente:

Cosa fácil habría de serme adquirir la confianza del empresario, obrando con paciencia y disimulo... En todo caso, al oponerse a nuestros deseos, nos fugaríamos por el Isana, y, cualquier día enfrentándome a mi enemigo le daría muerte, en presencia de Alicia y de los enganchados. Después, cuando nuestro cónsul desembarcara en Yaguanari, en vía para el Guaracú, con una guarnición de gendarmes, a devolvernos la libertad, exclamarían mis compañeros: El implacable Cova nos vengó a todos y se internó por este desierto. 28

De referirnos ahora a la segunda forma de exaltación de la personalidad, o sea, de la pasión por lo diferenciador, que llevaba al romántico hasta a considerarse único, sin paralelo humano, cuando no por otras cosas al menos en sus penas, véase lo típico del siguiente fragmento en que Cova se compara con su infortunado amigo Ramiro Estévanez:

Todo nos lo hemos dicho y ya no tenemos de que conversar. Su vida de comerciante..., de minero..., de curandero..., carece de relieve y de fascinación; ni un hecho descollante sobre lo común. En cambio, yo sí puedo enseñarle mis huellas en el camino, porque si son efímeras, al menos no se confunden con las demás. 29 
He ahí, pues, además de la pedantería romántica, el desprecio por lo vulgar, por lo cotidiano, por lo falto de relieve; y su admiración sin límites, en cambio, por to heroico, lo único, lo inconfundiblemente personal, producto de ese individualismo de extrema, en pugna siempre con todo lugar común de la vida diaria, con todo lo usual, entre cuyas manifestaciones hallamos también, como en este caso, ese tipo de romanticismo aventurero y de acción del que es Byron, probablemente, su máximo representante.

Ahora bien, en la misma esencia del movimiento romántico vamos a encontrar otro tipo de aventurerismo, esta vez íntimo, subjetivo, y más frecuente que el anterior, representado por la búsqueda sin tregua del ideal femenino, para muchos no otra cosa que un nuevo medio de intoxicación pasional, como el anterior.

Lo cierto es, sin embargo, que para el romántico hay un eterno ideal de mujer que rara vez cristaliza en la realidad, aunque se crea mil veces a punto de alcanzarlo, acaso porque, como se ha dicho más de una vez, el romántico esté realmente enamorado de su propio sueño, o del amor en sí.

En una forma u otra, y cualquiera que sea la explicación intentada, es indudablemente éste uno de los más persistentes elementos que vamos a encontrar en el romanticismo de La vorágine, observable ya desde Tierra de promisión. Por ello suspirará Cova, una y otra vez, por el amor ideal que no llega jamás, mientras el tedio le corroe el alma.

Hoy, como nunca, siento nostalgia de la mujer ideal y pura, cuyos brazos brinden serenidad para la inquietud, frescura para el ardor, olvido para los vicios y pasiones. Hoy, como nunca, añoro lo que perdí en tantas doncellas ilusionadas, que me miraron con simpatía y que en el secreto de su pudor halagaron la idea de hacerme feliz. 30

O se lamentará como René por la ausencia de un corazón femenino que comparta sus sueños:

Aquella tarde rendí mi ánimo a la tristeza y una emoción romántica me sorprendió con vagas caricias... Y pensaba con dolorida inconformidad: i $\mathrm{Si}$ tuviera ahora a quien ofrecerle este armiñado ramillete de plumajes, que parecen espigas blancas! i $\mathrm{Si}$ 
alguien quisiera abanicarse con este alón de "codua" marina, donde va prisionero el iris! i Si hubiera hallado con quien contemplar el garcero nítido, primavera de aves y colores! $\mathbf{3 1}$

Y así lo veremos siempre, a través de la llanura y de la selva, con ese sueño de lo que no se encuentra; con todas sus ansias de "ternuras lejanas", e idealizando ya a Alicia, ya a la madona Zoraida, para volver ineludiblemente a la misma angustia, a la misma queja.

En el estudio de La vorágine advertimos por consiguiente un fuerte contenido romántico, que consideramos centrado fundamentalmente en la personalidad de su héroe, Arturo Cova, en quien ni siquiera ese concepto del destino implacable del romanticismo estará ausente. Por ello, cuando la pasión estalla para quebrarse más tarde en la impotencia; cuando tiende la fantasía sus alas que la realidad destruye; cuando la mujer ideal se convierte en horizonte que jamás se alcanza, y tanto el propio Cova como sus compañeros son arrastrados por el torbellino incontenible de la selva, en los labios del héroe habrá siempre un grito de protesta contra el "fatum implacable" que los persigue "sin otro delito que el de ser rebeldes, sin otra mengua que la de ser infortunados." 32

\section{Otto Olivera, Tulane University, New Orleans, La.}

\section{$\mathrm{N} O \mathrm{TAS}$}

1 José Eustasio Rivera, Tierra de promisión, 2da. edic., Santiago de Chile, Edit. Ercilla, 1940, p. 15.

2 Atala, René, El último abencerraje, Santiago de Chile, Edit. Ercilla, 1938, p. 87.

3 Antología de poetas liricos colombianos, Bogotá, Imprenta Nacional, 1936, I, 43-44.

4 El mirador de Próspero, Madrid, Editorial América, ?, II, 182.

5 "Tres novelas ejemplares", Sur, vI, 1936, p. 63.

6 Arturo Torres Rioseco, Novelistas contemporáneos de América, Santiago de Chile, Edit. Nascimiento, 1939, p. 66. 
7 La Vorágine, New York, Edit. Andes, 1929, p. 132.

8 Ibid., p. 141.

9 Ibid., p. 108.

10 Ibid., p. 245.

11 Ibid., p. 30.

12 Ibid., p. 11.

13 Ibid., p. 12.

14 Nos referimos a lo que pudiera llamarse romanticismo "esencial", "puro". En otra parte hemos dicho: En la raíz" de todo el movimiento hay, pues, tna especial actitud vital que parte de la expresión sin freno de los más intimos, "puros" y, con frecuencia, vagos estados emocionales.

15 La VTorágine, p. 262.

16 Rousseau and Romanticism, Boston-New York, Houghton Mifflin Co., 1918 , p. 161.

17 Las confesiones, París, Garnier Hermanos, ? I, 44.

18 Atala, René, El último abencerraje, edic. cit., p. 77.

19 Werther, París, Garnier y Hnos., 1895, p. 9.

20 Rivera, op. cit., p. 63.

21 F. L. Lucas, The decline and fall of the Romantic ideal, New York, The McMillan Co., 1937, p. 109.

22 Edic, cit., p. 233.

23 Ibid., p. 171.

24 Op. cit., p. 139.

25 Rivera, op. cit., p. 242.

26 Rousseau, op. cit., I, 188.

27 Rivera, op. cit., p. 57.

28 Ibid., Đ. 237.

29 Ibid., D. 296.

30 Ibid., p. 308.

31 Ibid., p. 141.

32 Ibid., D. 130. 


\section{BIBLIOGRAFIA}

LIBROS

Babbit, Irving. Rousseau and Romanticism, Boston-New York, Hougton Mifflin Co., 1918.

Byron, G. G. Selected poems of Lord Byron, New York, T. T. Crowell \& Co., 1893.

Casa, Enrique. La novela antioqueña, México, Instituto Hispánico de los E. U., 1942.

Cento, M. I. La novela hispanoamericana, Santiago de Chile, Edit. Nascimento, 1934.

Chateaubriand, R. Atala, René, El último abencerraje, Santiago de Chile, Edit. Ercilla, 1938.

Gandía, Enrique. Origenes del romanticismo, Buenos Aires, Edit. Atalaya, 1946.

García-Prada, Carlos. Antología de líricos colombianos, Bogotá, Imprenta Nacional, 1936.

Goethe, W. Werther, París, Garnier y Hnos., 1895.

Gómez Restrepo, Antonio. José Eustasio Rivera, Colección Samper Ortega de literatura colombiana, viIr, Colombia, Edit. Minerva.

Lucas, F. L. The decline and fall of the Romantic ideal, 3rd. Edition, New York, McMillan Co., 1936.

Meléndez, Concha. La novela indianista en Latinoamérica, Madrid, Hernando y Cía., 1934.

- Tres novelas de la naturaleza americana, Signos de Iberoamérica, México, Imprenta Manuel León Sánchez, 1936.

Ortega, José J. Historia de la literatura colombiana, 2da. edic. Bogotá, Cromos, 1935.

Otero Muñoz, Gustavo. Resumen de historia de la literatura colombiana, 2da. edic., Bogotá, Edit. ABC, 1937.

Rivera, José Eustasio. Tierra de promisión, 2da. edic., Santiago de Chile, Edit. Ercilla, 1940.

—. La Vorágine, 9na. edic., New York, Edit. Andes, 1929.

Rodó, José E. El mirador de Próspero, Madrid, Edit. América, II, ?

Rousseau, J. J. Las confesiones, Paris, Garnier y Hnos., ? 
Sánchez, L. A. América, novela sin novelistas, 2da. edic., Santiago de Chile, Edit. Ercilla, 1940.

—. Historia de la literatura americana, Santiago de Chile, Edit. Ercilla, 1937.

Sanín Cano, B. Letras colombianas, México, Fondo de Cultura Económica, 1944.

Torres Ríoseco, A. La novela en la América hispana, Berkeley, California, University of California Publications in Modern Philology, ?.

- Novelistas contemporáneos de América, Santiago de Chile, Edit. Nascimento, 1939.

- The epic of Latin American literature, New York, London, Oxford University Press, 1942.

Vaughan, Ch. E. The Romantic revolt, New York, C. Scrimber's Sons, 1923.

Vitier, Medardo. El romanticismo, Apuntaciones literarias, La Habana, Edit. Minerva, 1935.

REVISTAS

Chasca, Edmundo de, El lirismo de "La Vorágine", Revista Iberoamericana, xxv, 1947, pp. 73-90.

G. S. The vortex, The Saturday Review of Literature, III, 1935, p. 25.

García Prada, Carlos, E1 paisaje en la poesía de Rivera y Silva, Hispania, XXIII, 1940, pp. 37-48.

Lovejoy, A. O. The meaning of Romanticism for the historian of ideas, Journal of the History of Ideas, In, 1941.

- On the discrimination of the Romanticism, P. M. L. A., xxxrx, 1924, pp. $229-253$.

Marinello, Juan, Tres novelas ejemplares, Sur, vi, 1936, pp. 59-75.

Maya, Rafael, Aspectos del romanticismo en Colombia, Revista Iberoamericana, virr, 1944, pp. 275-289.

Montenegro, E. La Vorágine, The Saturday Reviere of Literature, v, 1928, p. 302.

Neale-Silva, E., Factual Bases of "La Vorágine", P. M. L. A., Liv, 1939, pp. 316-331.

Romanticism: a symposium, P. M. L. A., Lv, 1940, pp. 1-60.

Sánchez, L. A., El paisaje en la literatura americana, elemento desconocido aunque dominante, Revista Iberoamericana, II, 1940, pp. 389-399.

Torres-Rioseco, A., Nuevas tendencias en la novela, Revista Iberoamericana, r, 1939, pp. 91-94. 
